\title{
Reimagining Our Relationships with Patients: A Perspective from the Keystone IV Conference
}

\author{
Larry A. Green, MD, and James C. Puffer, MD
}

Substantial efforts to redesign health care delivery are underway in the United States, including primary care, without attention to what has historically been known as "the personal physician." The American Board of Family Medicine Foundation convened the Keystone IV Conference to reflect on the nature of personal doctoring and particularly what promises personal physicians might appropriately make and keep with their patients, going forward in new systems of care. This commentary describes the conference and its participants and provides an overview of manuscripts prepared by attendees that together comprise a written record of the conference. The authors conclude that a properly prepared and positioned personal physician practicing within a modernized primary care platform is a critical means of achieving better health and health care that is affordable, revitalizing the health professions workforce, and restoring population health in the United States. There is urgency to join with patients and colleagues to create the conditions under which people can have a personal physician of their choosing who knows them well, will stick with them as they wish, and be accountable for their receiving care that is appropriate for them as unique persons, with particular goals, preferences, and capabilities. $(\mathrm{J}$ Am Board Fam Med 2016;29:S1-S11.)

Keywords: Doctoring, Family Medicine, Family Physician, Health Care Delivery, Personal Physician, Population Health, Primary care, Professionalism, Social Justice

More than 50 years ago, T.F. Fox ${ }^{1}$ penned a seminal article for the Lancet in which he defined the personal physician and described the centrality of the physician-patient relationship to this definition:

The doctor we have in mind, then, is no longer a general practitioner and by no means always a family practitioner. His essential characteristic, surely, is that he is looking after people as people and not as problems. He is what our

This article was externally peer reviewed.

Submitted 10 May 2016; revised 10 May 2016; accepted 10 May 2016.

From the Department of Family Medicine, University of Colorado, Denver (LAG); The American Board of Family Medicine, Lexington, KY (JCP).

Funding: none.

Conflict of interest: LAG is board chair of the board of directors of the ABFM Foundation, which funded Keystone IV. JCP is employed by the ABFM as its president and chief executive officer and serves as president of the ABFM Foundation.

Corresponding author: Larry A. Green, MD, Department of Family Medicine, University of Colorado Denver, 12631 East 17th Ave, Room 3521, Mail Stop F496, Academic Office 1, Aurora, CO 80045-0508 (E-mail: larry.green@ ucdenver.edu). grandfathers called "my medical attendant" or "my personal physician," and his function is to meet what is really the primary medical need. A person in difficulty wants in the first place the help of another person on whom he can rely as a friend-someone with knowledge of what is feasible but also with good judgment on what is desirable in the particular circumstances and an understanding of what the circumstances are. The more complex medicine becomes, the stronger are the reasons why everyone should have a personal doctor who will take continuous responsibility for him, and, knowing how he lives, will keep things in proportion-protecting him, if need be, from the zealous specialist. The personal doctor is of no use unless he is good enough to justify his independent status. An irreplaceable attribute of personal physicians is the feeling of warm personal regard and concern of doctor for patient, the feeling that the doctor treats people, not illnesses, and wants to help his patients not because of the interesting medical problems they 
may present but because they are human beings in need of help.

At a time when American medicine is becoming increasingly controlled, systematized, and commoditized-some have likened the phenomenon to the "McDonaldization" of medicine ${ }^{2}$ - physicians are becoming increasingly frustrated, angry, and burned out. Many have advocated for paying closer attention to professional satisfaction as a means to improve patient care and health system sustainability. ${ }^{3}$ To explore further the relationships among personal doctoring, professional satisfaction, and health system vitality, the American Board of Family Medicine Foundation convened a recent meeting in Keystone, Colorado, the first in the series of continuing conferences to memorialize the contributions G. Gayle Stephens made to the specialty of family medicine and to continue his legacy of consistent intellectual leadership in the development of medicine as a profession. ${ }^{4}$

\section{Background}

Dr. Stephens was one of the founders of family medicine and profoundly affected the creation and implementation of this young specialty, officially established in 1969. From time to time, Dr. Stephens invited a few people, mostly at their own expense, to gather and reflect on the nature and condition of medical practice, the needs of people, and how the care of individuals, families, and communities could be enhanced by the profession of medicine. These conferences were never conceived as strategic planning events; rather, the distillation of the deliberations that occurred provided foundations from which strategic directions were set and actions were taken. They euphemistically became known as the "Keystone Conferences," even when they did not occur at Keystone, Colorado. The inaugural conference for the G. Gayle Stephens Keystone Conference series constituted the fourth "Keystone Conference." In this $7 A B F M$ supplement we desire to document and share the deliberations that occurred at this Keystone conference, which focused on the following question: "What promises will a personal physician make to her/his patients going forward in the evolving health care system of the United States, particularly in terms of when and where he/she will be there for his/her patients?"
An intergenerational planning committee determined the topics and organization of Keystone IV and identified 57 attendees. These attendees included physicians at different stages of their careers-from those just entering practice to those with $>40$ years of experience in diverse settings. Many attendees were family physicians, and others included patients, patient advocates, physicians from other disciplines, and clinicians/scientists/ leaders in other professions (see the Appendix). Records from prior Keystone conferences and a selection of background publications pertinent to the major theme of the conference were posted in advance on the conference website (www.gaylestephensconference.com). Four preparatory articles were commissioned and presented at the conference, and a few reactors were identified in advance to offer commentary about the ideas in these articles. These presentations, reactions, and ensuing plenary conversations were guided by the conference facilitator, Dr. Robert Graham, as they were streamed to the Internet and recorded. Smaller breakout groups extended the discussion and seeded further ideas for subsequent discussion at the conference. Almost all attendees were present for the entire conference (Figure 1), sharing breaks and meals together where ideas and opinions were considered further. Each attendee was invited to submit 1 or more written promises that he/she endorsed for personal physicians, and $>40$ individuals did so. After the conference, the planning committee organized a plan to prepare a set of manuscripts based on the conference, and agreement was reached with the Fournal of the American Board of Family Medicine to publish this peer-reviewed supplement as the historic record of Keystone IV.

\section{Content of the Conference}

This supplement can be read to good effect from beginning to end, as sequenced. It can also be read selectively, and to assist readers in finding information they want to access, we highlight here the content of each article.

John Frey ${ }^{5}$ provides an insightful tribute to Dr. Stephens, including benchmark messages about a personal physician's responsibilities. He underscores the criticality of integrating clinical information with patient values, thereby allowing the physician to serve in the role of a guide, rather than an arbiter or a judge of a patient's motives. He joins 
Dr. Stephens's frequent and vocal admonitions by warning against arrogance, self-satisfaction, laziness, and the failure to resist organizations that create barriers, both structural and economic, that erode the continuing connection between doctors and patients.

Rosemary Stevens ${ }^{6}$ reprises her message from Keystone III, pointing out that family medicine, as a specialty, still lacks a well-recognized identity within the larger health care system. She unambiguously claims that the major job of Keystone IV is teasing out which past decisions constrain what can be done now, and which decisions can be made now to recharge family medicine's mission through "workable ideas."

Will Miller ${ }^{7}$ effectively uses "tempo" as a reflection of health and to focus on the current rate and rhythm of clinical practice and the lives people live. He claims that personal physicians are "relationship jugglers" in a frightening, isolating, fragmenting, overpopulated world where people need all the many kinds of helpful relationships they can get.

Kim Griswold ${ }^{8}$ reveals the complexity of what "place" means for personal physicians, suggesting that one of the most important promises to be made is to meet patients where they are-emotionally and geographically. She also observes that the current trend toward team-delivered care does not squeeze out the personal physician, but rather allows the personal physician sufficient space to do what he or she does best- "the art of paying exquisite attention to patients."

David Loxterkamp 9 claims that the most valuable gift we can offer another human being is the time we spend with them, and that effective doctoring hinges on a sense of timing, grounded in trust, often in the space between illness and health. He reports moments that fill both the patient and doctor with awe, "for they have witnessed [together] new growth sprouting from empty time and find themselves fully engaged with the "other."

Kurt Stange ${ }^{10}$ offers reactions and an insightful synthesis of the conference. In his article he claims that "holding on and letting go were the key undercurrent challenges of the conference." He notes Dr. Stephens's writings about family medicine being "counterculture" and explores

\section{Figure 1. Keystone IV group photo.}

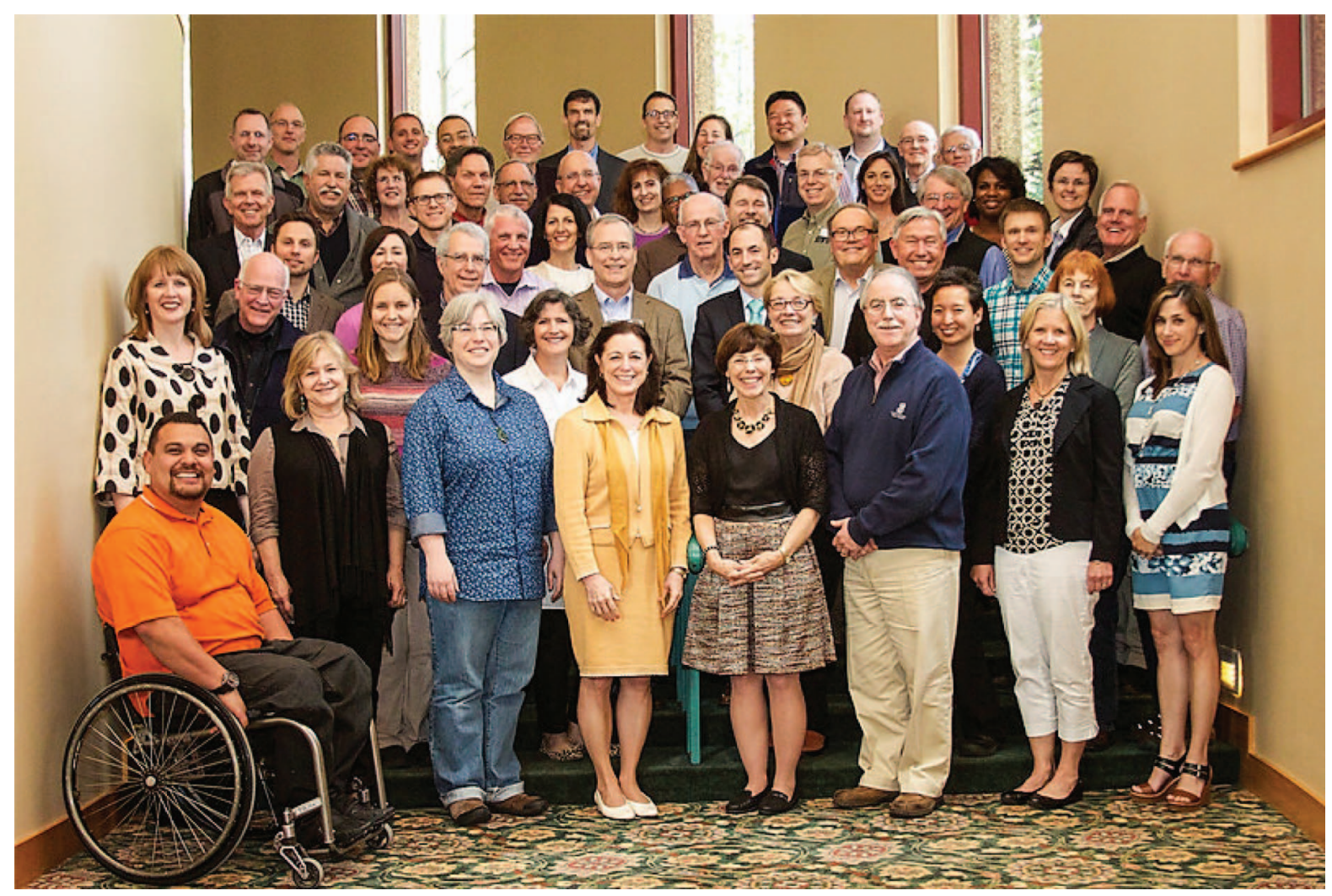


Etz

I will be held accountable to those who need me. I will be there for you. Attentive and fully present. I will care for you when you have no need and you do not ask. I will center that care in your lived experience of health and illness, knowing you over time. I will be here for you now, over time and across distance, in ways that foster the feeling of wholeness and belonging. I will provide centered care, personal care, expert care, and experiential care, despite economic, technological, and political distractions that threaten to enter the healing place we create together. Because I know you, I will be able to use the best knowledge, best tailored to meet our shared understanding of your goals and aspirations.

Miller

We promise to always be present, as clinically competent partners, and work with you, your family and friends, and our communities for better health. It is a collective promise by our personal, relationshipcentered team. My individual promise is to ensure the collective one. This is a dream that will not sleep; a promise we will keep. This is the hunger we will fulfill.

Griswold

Wherever care is delivered, we can promise to meet and delight in patients where they are; continue to cultivate communities of solution; remember the place of touch in healing.

Loxterkamp

Let's pledge to give patients our undivided time. Let's create treatment plans that are built on the bedrock of trust. And let's secure these promises with a commitment to regain control over our professional time and the rule by which we govern it.

Stream et al

We must also renew promises: our promise to maintain a broad scope of training and practice for family physicians to meet patient and community needs; our promise to collaborate with other primary care professionals and stakeholders outside of medicine; our promise to embrace patients and patient advocates as partners in our work at the patient/organizational/systems levels; and our promise to be leaders in our communities with regard to bridging public and behavioral health.

Waters et al

First and foremost, we will be unwavering in our commitment to relationship, to flatten the power differential between patient and health team, and to be present especially at those critical transitions of care when our patients need us most. We will also remember that our purpose as healers and our commitment to the whole patient includes a call to action outside our clinics. We promise to advocate for relationship-centered care for all as the foundation for a new health care system. Inherent in this goal is working toward universal access to health care, so that those currently unable to establish a relationship with a health team can do so. Innovations at the clinic and system levels that enhance accessibility, continuity, and coordination of care will ultimately enhance the strength of patient-care team relationships. We also acknowledge our mandate to bear witness to the powerful impact of the social, economic, and political determinants of health, to persistent institutional racism, and to unique hardships faced by those new to this country.

Schroeder

I will work with you to maximize your health and well-being. I will try to get to know you and understand what you want from me. I will try to meet your needs, including sites of care. I or one of my team members will be available for you. what it might mean to be counterculture in the current era. He observes that family medicine has served as a "buffer for a disjointed, depersonalizing, avaricious health care system" and warns that "the buffering capacity is nearly expended."

The anthropologist Rebecca Etz ${ }^{11}$ observed carefully the entire conference, studied the conference recordings and all the promises offered by attendees, searched the relevant literature, and derived what can be considered an outcome article for the conference. She connects personal doctoring with the mission, foundational principles, and ideals of the specialty of family medicine. She summarizes a feeling permeating the conference: "If there is one thing in 2015 on which personal doctors can agree, it is that they feel under fire, holding strong, while also witnessing a certain amount of withering on the vine. It is as if they are bearing witness to the potential end of an era in which people in medicine matter." She concludes that there is no single promise for the personal physician to make, and she articulates several (Table 1). Her analysis exposed 2 foundational promises that emanated from the proceedings: "We will be held accountable. We will return to our roots."

Glen Stream, the president of Family Medicine for America's Health, an organization recently established by national professional organizations, sees with his coauthors ${ }^{12}$ that family medicine has immediate opportunities to be less about counterculture and more about the innovation necessary for personal doctoring. This article advises those who would be personal physicians to train for and sustain a broad scope of practice to meet individual and community needs, to embrace patients and patient advocates as partners, and to lead in their local communities to bridge public and behavioral health.

Three articles report observations and conclusions of coauthors from 3 generations of practicing physicians: the youngest, the oldest, and those holding forth in between. Richard Waters et $\mathrm{al}^{13}$ report rediscovering at the conference that relationship-centered care and social justice are core 
tenants of family medicine, and they confess that "we haven't heard in our training years that family medicine itself was rooted in reform, with a legitimate, obligatory interest in transforming the systems on behalf of patients." Frederick Chen crystalized for the planning committee the conference question. He and his coauthors ${ }^{14}$ capture and report the lived experience and importance of a "sandwich" generation of personal physicians. This generation lives each day with the palpable tension between "relationships and productivity" and endures a lack of solutions for resolving conflicts between what systems require and what patients need. Jack Colwill and his coauthors ${ }^{15}$ have the long view and know through vast experience the realities of life and clinical practice. They have seen and experienced firsthand the difference personal physicians can make, and they plead for practice and educational approaches that enable people to have a personal physician "when life's crises arrive-eventually for everyone."

As the conference proceeded, several attendees simply could not resist formulating actionable steps necessary for people to have a personal physician. Jen DeVoe et $\mathrm{al}^{16}$ authored an article that presents possible, plausible steps needing immediate attention. They champion the need to reimagine the personal relationship between personal physician and patient as today's countercultural movement for primary care. More important, they call out the need to harness the recent advances in information technology, team-based care, and population health to fortify this relationship rather than detract from it.

A fitting coda to the proceedings was provided by Steve Schroeder. ${ }^{17}$ In his insightful perspective on the conference, this accomplished general internist challenges family physicians to be a voice for social justice, working with allies to be vocal and expert champions of "personomics."

\section{The Promises}

The conference did not neglect its question, and it yielded a buffet of challenging and inspiring promises. Several articles in this supplement explicitly articulate promises that personal physicians should make and keep going forward. We have organized these in Table 1 for easy reference.

\section{Comments}

Dr. Fox argued that the more complex medicine becomes, the stronger are the reasons why everyone should have a personal doctor who will take continuous responsibility for each of his or her patients. We concur with this assumption and with the recent call by Woollard ${ }^{18}$ for a pronounced return to "effective healing relationships that endure over time and over place of care."

We also recall the nationally representative survey results from the Future of Family Medicine ${ }^{19}$ that found that people across the United States wanted personal physicians but no longer believed they existed. Indeed, the current environment as voiced at this conference makes personal doctoring difficult, if not impossible. It is entirely plausible that without contravening action, the people of the United States will not have a personal physician whom they consider to be "my doctor." Perhaps that is the future some seek; it is not likely to be the future desired by those wanting to be well and to avoid suffering.

We also are struck by the continuing relevance and timeliness of a 1964 report unknown to us or other conference attendees until after the conclusion of Keystone IV, "The Future of the Personal Physician." 20 This report, the second in a series of seminars focused on critical health care issues of the 1960s, claimed:

There is growing concern that the fragmentation of care among many specialties may well jeopardize the personal relationship between doctors and patients, built as it must be on long-term cooperation in health as well as in sickness. There is increasing realization that such a close relationship can mean not only quicker and more accurate diagnosis, but also more effective treatment. In addition, although doctors have less "time to listen," patients have higher expectations of medicine and make more demands on their physicians.

A half century later this concern is still growing. Our country finds itself in the disturbing situation of our residents having poorer health and shorter lives than the populations living in peer nations, despite stunning increments in knowledge, specialization, and expenditures. ${ }^{21}$ Widespread agreement is abundantly evident that the current situation cannot and should not persist, and that we should and can unite around the health policy goals known as the "triple 
aim": better health care that we can afford that yields better health. ${ }^{22}$

Evidence firmly establishes that a strong foundation of primary care results in better care, contained costs, better health, and also reduced disparities within populations. ${ }^{23}$ The current situation in the United States is what the evidence suggests we should have with a weak primary care infrastructure; few would dissent against the notion that our country's primary care delivery system is underdeveloped and undercapitalized. Substantial efforts are underway to redesign this largest platform of health care delivery to modernize it for outstanding primary care in the information age. ${ }^{24}$

No such efforts are underway to ensure that people have a personal physician. Our own viewpoint is that personal physicians are part of the solution to our nation's most important and embarrassing health and health care concerns, those requiring elegant teamwork and partnerships, continuous information linkage, deep personal knowledge of individuals seeking care, accountability, and trust. They are the bulwarks against the continuing "McDonaldization" of medicine, which, if not reversed, will result in "unreasonable systems that deny the humanity, the human reason, of the people who work within them or are served by them."2

There is great urgency to complete the redesign of the primary care platform (ie, currently known as the patient-centered medical home) and to create the conditions under which people can have a personal physician of their choosing who knows them and will stick with them as they wish. Such a physician must not prespecify the problems his or her patients are allowed to have and must excel at customizing each patient's particular situation to what health care has to offer. Such physicians must be great at adapting what is possible to what is desired and prudent for each patient. The new personal physician on the modernized primary care platform is a critical means of achieving the triple aim, revitalizing the health professions workforce, and restoring population health in the United States.

\section{Conclusion}

We extend again our thanks to the American Board of Family Medicine Foundation for its financial support, the conference planning committee, all the Keystone IV conference attendees for their personal support and contributions to the confer- ence, all the authors of this supplement, and especially to the Stephens family for allowing the use of their name to establish this continuing conference series in honor of Dr. Gayle Stephens. We invite readers to the conference website to view any or all of the conference presentations and summary videos suitable for use in teaching/learning situations (www.gaylestephensconference.com).

Being a personal physician in the information age ... here lies one of the most exciting and challenging career opportunities in history for the next generation of physicians. This conference confirmed we should proceed apace to help a substantial portion of our existing and future physician workforce to become outstanding personal physicians who will partner with patients and work adaptively with the rest of an ever-changing health care delivery system. Why delay any longer?

The authors especially thank the members of the Keystone IV Planning Committee: Frederick Chen, MD, MPH, University of Washington Department of Family Medicine, Seattle; Jack Colwill, MD, University of Missouri Department of Family and Community Medicine, Columbia; Jennifer DeVoe, MD, DPhil, Oregon Health \& Science University Department of Family Medicine, Portland; Tricia Elliot, MD, University of Texas Medical Branch Department of Family Medicine, Galveston; John Frey, III, MD, University of Wisconsin Department of Family Medicine, Santa Fe, NM; Robert Graham, MD, Milken Institute School of Public Health, Kansas City, MO; Lauren Hughes, MD, MPH, University of Michigan Department of Family Medicine; Ann Arbor; Larry Green, MD, Chair, Planning Committee, University of Colorado Department of Family Medicine, Denver; Jim Puffer, MD, Ex-officio Member, American Board of Family Medicine, Lexington, KY; Linda Niebauer, Staff Member, Planning Committee, University of Colorado Department of Family Medicine, Denver.

\section{References}

1. Fox TF. The personal doctor and his relation to the hospital. Lancet 1960;2:743-60.

2. Dorsey ER, Ritzer G. The McDonaldization of medicine. JAMA Neurol 2016;73:15-6.

3. Friedberg MW, Chen PG, Van Busum KR, Aunon FM, Pham C, Caloyeras JP, Mattke S, Pitchforth E, Quigley DD, Brook RH, Crosson JFJ, Tutty M. Factors affecting physician professional satisfaction and their implications for patient care, health systems, and health policy. Santa Monica, CA: RAND Corporation, RR-439-AMA, 2013. Available from http://www.rand.org/pubs/research_reports/ RR439.html. Accessed June 22, 2016.

4. Green LA, Puffer JC. The American Board of Family Medicine Foundation inaugurates the G. Gayle Stephens Keystone Conference series. Ann Fam Med 2015;13:391-2. 
5. Frey J. G. Gayle Stephens and wrestling the bear: a perspective from the Keystone IV conference. J Am Board Fam Med 2016;29(Suppl 1):S12-S14.

6. Stevens R. Recharging family medicine: a perspective from the Keystone IV conference. J Am Board Fam Med 2016;29(Suppl 1):S15-S18.

7. Miller W. Unfilled hunger: seeking relationships in primary care-a perspective from the Keystone IV Conference. J Am Board Fam Med 2016; 29(Suppl 1):S19-S23.

8. Griswold KS. Changing places: where will we be with our patients? a perspective from the Keystone IV Conference. J Am Board Fam Med 2016;29(Suppl 1):S24S27.

9. Loxterkamp D. The time of our lives: a perspective from the Keystone IV conference. J Am Board Fam Med 2016;29(Suppl 1):S28-S31.

10. Stange K. Holding on and letting go: a perspective from the Keystone IV conference. J Am Board Fam Med 2016;29(Suppl 1):S32-S39.

11. Etz R. People are primary: a perspective from the Keystone IV conference. J Am Board Fam Med 2016;29(Suppl 1):S40-S44.

12. Stream G, DeVoe JE, Hughes LS, Phillips RL Jr. Accelerating momentum toward improved health for patients and populations: family medicine as a disruptive innovation - a perspective from the Keystone IV conference. J Am Board Fam Med 2016;29(Suppl 1): S60-S63.

13. Waters R, Stoltenberg M, Hughes LS. A countercultural heritage: rediscovering the relationship-centered and social justice roots of family medicine-a perspective from the Keystone IV Conference. J Am Board Fam Med 2016;29(Suppl 1):S45-S48.

14. Chen FM, Bliss E, Dunn A, et al. The generation in between: a perspective from the Keystone IV conference. J Am Board Fam Med 2016;29(Suppl 1):S49S53.

15. Colwill JM, Frey JJ, Baird MA, Kirk JW, Rosser WW. Patient relationships and the personal physician in tomorrow's health system: a perspective from

\section{Appendix 1}

\section{Keystone IV Attendees}

Macaran Baird, MD

Chair, University of Minnesota Department of Family Medicine and Community Health

420 Delaware Street, SE; MMC 381, 6 to 240 $\mathrm{PWB}$

Minneapolis, MN 55445

Kathleen Barnes, MD, MPH

FM Resident, Group Health Cooperative Family Medicine Residency the Keystone IV conference. J Am Board Fam Med 2016;29(Suppl 1):S54-S59.

16. Devoe J, Barnes K, Morris C, et al. The personal doctoring manifesto: a perspective from the Keystone IV conference. J Am Board Fam Med 2016; 29(Suppl 1):S64-S68.

17. Schroeder SA. Social justice as the moral core of family medicine: a perspective from the Keystone IV conference. J Am Board Fam Med 2016; 29(Suppl 1):S69-S71.

18. Woollard RF. When evidence and common sense collide: resident hours and systems of care. Can Fam Physician 2013;59:125-7.

19. Martin JC, Avant RF, Bowman MA, et al; Future of Family Medicine Project Leadership Committee. The Future of Family Medicine: a collaboration of the family medicine community. Ann Fam Med 2004;2(Suppl 1):S3-32.

20. Harlow AH, Jr. The Future of the Personal Physician, the record of the second in a series of national symposiums on The Health Care Issues of the 1960 's, conducted as a public interest activity of Group Health Insurance, Inc. New York. Group Health Insurance, Inc.; 1964.

21. Woolf SH, Aron L, eds.; Panel on Understanding Cross-National Health Differences Among High Income Countries; Committee on Population; Division of Behavioral and Social Sciences and Education; National Research Council; Board on Population Helath and Public Health Practice; Institute of Medicine. U.S. health in international perspective: shorter lives, poorer health. Washington, DC: National Academies Press; 2013.

22. Berwick DM, Nolan TW, Whittington J. The triple aim: care, health and cost. Health Aff (Millwood) 2008;27:759-69.

23. Starfield B, Shi L, Macinko J. Contribution of primary care to health systems and health. Milbank Q 2005;83:457-502.

24. Patient-Centered Primary Care Collaborative [homepage]. Available from: www.pcpcc.org. Accessed March 9, 2016.

1305 E. Howell Street, \#101

Seattle, WA 98122

Andrew Bazemore, MD

Director, Robert Graham Policy Center

1133 Connecticut Avenue, NW, Ste. \#1100

Washington DC 20036

Erika Bliss, MD

CEO, Qliance Medical Management, Inc.

10420 NE 55th Street

Kirkland, WA 98033 
Marjorie Bowman, MD, MPA

Associate VP, Health Research, Wright State University

3943 Sable Ridge Drive

Bellbrook, OH 45305

Jeffrey Cain, MD

Associate Professor, University of Colorado Department of Family Medicine

12631 E. 17th Avenue, F496

Aurora, CO 80045

Kendall Campbell, MD

Co-Director, Center for Underrepresented Minorities in Academic Medicine

Florida State University Department of Family

Medicine and Rural Health

1115 W. Call Street

Tallahassee, FL 32306

Frederick Chen, MD

Chief of Family Medicine, Harborview Medical Center

Professor, University of Washington Department of Family Medicine

325 Ninth Avenue

Seattle, WA 98104

Jack Colwill, MD

University of Missouri Department of Family and Community Medicine

M226 Medical Sciences Building

Columbia, MA 65212

Craig Czarsty, MD

Vice Chair, American Board of Family Medicine Foundation

Past Chair, ABFM Board of Directors

Private Practice in Oakville, CT

314 Main Street

Oakville, CT 06779

Frank deGruy, MD

Woodward-Chisholm Professor and Chair

University of Colorado Department of Family Medicine

12631 E. 17th Avenue, F496

Aurora, CO 80045
Karen DeSalvo, MD, MPH, MSc

National Coordinator for Health Information Technology

200 Independence Avenue, SW, Ste. \#729D

Washington, DC 20202

Jennifer DeVoe, MD

Chief Research Officer, OCHIN and practicing physician

Oregon Health \& Science University Department of Family Medicine

2615 SW Texas Street

Portland, OR 97219

Aaron Dunn, MD

Rural Family Physician

330 Maiden Street

Mineral Point, WI 53565

Jennifer Edgoose, MD, MPH

Faculty, University of Wisconsin-Madison Family Medicine Residency Program

15 N. Prospect Avenue

Madison, WI 53726

Tricia Elliott, MD

Director, University of Texas Department of Family Medicine Residency Program

301 University Boulevard

Galveston, TX 77555 to 1123

Ted Epperly, MD

President and CEO, Family Residency of Idaho 777 N. Raymond

Boise, ID 83704

Rebecca Etz, PhD

Cultural anthropologist, Virginia Commonwealth University Department of Family Medicine and Population Health

830 E. Main Street, Room \#629

Richmond, VA 23235

John Frey, III, MD

Professor Emeritus, University of WisconsinMadison Department of Family Medicine

And Community Health

8 Avenida de la Scala

Santa Fe, NM 87506 
Julea Garner, MD

Rural Family Physician

1995 Highway 62 to 413

Hardy, AR 72543

Rick Glazier, MD, MPH

President, North American Primary Care Research Group

Senior Scientist and Program Lead, Primary

Care and Population Health

Institute for Clinical Evaluation Sciences

University of Toronto Department of Family and Community Medicine

138 Lascelles Blvd

Toronto, ON M5B 1W8, Canada

Katherine Gold, MD, MSW, MS

James C. Puffer/ABFM Fellow at the Institute of Medicine

University of Michigan Departments of Family Medicine and Ob-Gyn

1805 Maryfield Drive

Ann Arbor, MI 48103

Robert Graham, MD

Director, F. Marian Bishop Fellowship Program Department of Health Policy

Milliken Institute School of Public Health

George Washington University

5049 Wornall Road, 7EF

Kansas City, MO 64112

Larry Green, MD

Epperson-Zorn Endowed Chair for Innovation

in Family Medicine

University of Colorado Department of Family Medicine

12631 E. 17th Avenue, F496

Aurora, CO 80045

Kim Griswold, MD, MPH, RN

Department of Family Medicine

Primary Care Research Institute

50 Saybrook Place

Buffalo, NY 14209

Kevin Grumbach, MD

Chair, University of California-San Francisco

Department of Family and Community Medicine

San Francisco General Hospital
1001 Potrero Avenue, Ward 83

San Francisco, CA 94110

Lauren Hughes, MD, MPH

Robert Wood Johnson Foundation Clinical Scholar

University of Michigan Department of Family Medicine

2020 Anderson Court

Ann Arbor, MI 481104

Carlos Roberto Jaén, MD, PhD

Chair, University of Texas Health Science-San Antonio Department of Family and Community Medicine

6605 Countess Adria

San Antonio, TX 78238

Paul James, MD

Donald J. and Anna M. Ottilie Chair, University of Iowa Department of Family Medicine

Carver College of Medicine

200 Hawkins Drive

Iowa City, IA 52242

Christina Kelly, MD

Faculty, Family Medicine Residency and $\mathrm{Ob}$ Fellowship

Darnall Army Medical Center at Fort Hood

2104 Addax Trail

Harker Heights, TX 76548

James Kennedy, MD

Practicing Family Physician

President, ABFM Board of Directors

PO Box 1312

Winter Park, CO 80482

Brian Kessler, DO

Professor of Family Medicine and Health Policy Fellow

Campbell University School of Osteopathic Medicine

2009 Stewart Street

Fuquay Varina, NC 27526

John Kirk, MD

Professor of Community and Family Medicine

Dartmouth Medical School

Practicing Internist/Geriatrician, New London Hospital 
2286 Stoneybrook Road

Grantham, NH 03753

Lynn Langdon, MS

Former Chief Operating Officer, American Board of Internal Medicine

1926 Brandywine Street

Philadelphia, PA 19130

France Légaré, $\mathrm{MD}, \mathrm{PhD}$

Canada Research Chair in Implementation of Shared Decision Making in Primary Care

Departments of Family and Emergency Medicine

Laval University-Québec

CHU de Quebec Research Center

7755 Saint-Viateur

Charlesburg, QC G1K 7P4 Canada

David Loxterkamp, MD

Practicing Family Doctor and Author

15 Salmond Street

Belfast, ME 04915

Jason Marker, MD, MPA

Rural Family Physician

Leader, FMAH Practice Transformation Core Team

President, AAFP Foundation

66642 SR 331

Wyatt, IN 46595

Lisa Maxwell, MD

Director, Family Medicine and combined Family Medicine/Emergency Medicine Residency Programs

Christiana Care Health System

President-elect, Association of Family Medicine Residency Directors

134 High Street

Mullica Hill, NJ 08062

Janet Meredith, MBA

Director, Community-based Participatory Research Program for Medical Students

2815 Clermont Street

Denver, CO 80207

Benjamin Miller, PsyD

Director, Eugene S. Farley, Jr. Health Policy Center
University of Colorado Department of Family Medicine

12631 E. 17th Avenue, F496

Aurora, CO 80045

William Miller, MD, MA

Chair, Department of Family Medicine

Lehigh Valley Hospital \& Health Network

707 Hamilton Street, eighth floor

Allentown, PA 18101

Carl Morris, MD

Director, Group Health Family Medicine Residency

University of Washington Department of Family Medicine

125 16th Avenue E

Seattle, WA 98112

Andrew Morris-Singer, MD

Founder and President, Primary Care Progress

1035 Cambridge Street, Ste. \#28A

Boston, MA 02141

David Nichols, MD, MBA

President and CEO, American Board of Pediatrics

111 Silver Cedar Court

Chapel Hill, NC 27514

Marci Nielsen, PhD, MPH

CEO, Patient-Centered Primary Care Collaborative

4605 Royal Birkdale Court

Lawrence, KS 66049

Bob Phillips, MD, MSPH

AAFP VP for Research and Policy

Practicing Family Physician

Professor of Family Medicine, Georgetown

University, George Washington University, and

Virginia Commonwealth University

3728 Morningside Drive

Fairfax, VA 22031

James C. Puffer, MD

President and CEO, American Board of Family Medicine

1648 McGrathiana Parkway, Ste. \#550

Lexington, KY 40511-1247 
Walter Rosser, MD

Former Chair of Four Departments of Family Medicine

Practicing Family Physician and Researcher

918 Jasper Court

Kingston, ON K7P 2A4, Canada

Sergio Sanchez

Member, High Plains Research Network's

Community Advisory Council

Operations Manager, Agri-Inject

117 S. Birch Street

Yuma, CO 80759

Julie Schirmer, LCSW

Director, Behavioral Science Education

Assistant Director, Family Medicine Clerkship

Tufts/Maine Medical Center School of Medicine, Department of Family Medicine

272 Congress Street

Portland, ME 04101

Steven Schroeder, MD

Distinguished Professor of Health and Health Care

Division of General Internal Medicine, Department of Medicine

University of California-San Francisco

10 Paseo Mirasol

Tiburon, CA 94920

Kurt Stange, MD, PhD

Distinguished University Professor, Department of Family Medicine and Community Health

Case Western Reserve University

19001 Oxford Road

Shake Heights, OH 44122

Rosemary Stevens, PhD, MPH

Medical and Social Policy Historian

Dewitt Wallace Distinguished Scholar at WeillCornell Medical College

171 W. 71st Street, \#3C

New York, NY 10023

Mark Stoltenberg, MD, MA

Resident, Department of Family and Community Medicine

Northwestern University, Feinberg School of Medicine

2717 W. Thomas Street, \#2

Chicago, IL 60622
Glen Stream, MD

President and Board Chair, Family Medicine for

America's Health

Practicing Family Physician

44818 Oro Grande Circle

Indian Wells, CA 92210

Richard Waters, and MD

Resident, University of Washington Department of Family Medicine

311 19th Avenue, E., \#1

Seattle, WA 98112

Jack Westfall, MD

Founder and Director, High Plains Research Network

University of Colorado Department of Family Medicine

Chief Medical Officer, Colorado HealthOP

9122 E. Tufts Circle

Greenwood Village, CO 80111

Stephens Family Member Attendees

Jan Cathcart

Savannah Cathcart

Dan Cathcart

Jean Lehman

Marty Shields

Billy Re Stephens

Julie Stephens

Lynn Stephens

Ken Stephens

Marc Stephens

Linda Niebauer

Coordinator, Keystone IV Conference

Director of Communications, Advancing Care

Together

University of Colorado Department of Family Medicine

12631 E. 17th Avenue, F496

Aurora, CO 80045

Sheryl Harrington

Meeting Staff Person, Keystone IV

Program Coordinator, Community Campus Partnership

University of Colorado Department of Family Medicine

12631 E. 17th Avenue, F496

Aurora, CO 80045 